Jurnal Ilmu Komunikasi UHO : Jurnal Penelitian Kajian Ilmu Komunikasi dan Informasi.

Volume 7, No. 1, Januari 2022, hlm 19-29

\title{
TEKNIK PARAFRASE UNTUK MENINGKATKAN JUMLAH TES ITEM PADA PROGRAM STUDI ILMU KOMUNIKASI UNIVERSITAS TERBUKA
}

\author{
Djoko Rahardjo ${ }^{1}$, Afriani ${ }^{2}$, Fauzy Rahman Kosasih ${ }^{3}$, \\ Universitas Terbuka \\ Jalan Cabe raya, Pamulang, Tangerang Selatan, Indonesia
}

\begin{abstract}
ABSTRAK
Di lembaga pendidikan, asesmen merupakan isu penting dalam upaya mengukur keberhasilan proses belajar siswa. Bank-soal sering mengalami kekurangan soal, terutama ketika buku-buku materi pokok baru diterbitkan sebagai bahan ajar. Jumlah item yang diperlukan dalam set pertanyaan tidak terpenuhi. Hal ini akan menurunkan kualitas asesmen. Tujuan penelitian ini adalah untuk memberikan alternatif bank soal dalam memperbanyak butir soal dengan teknik parafrase. Tahapan penelitian meliputi membuat prosedur parafrase, mengujicobakan kepada beberapa penulis tes, menentukan kategori parafrase, dan memutuskan teknik mana yang sesuai untuk tes stem atau item pertanyaan tertentu. Hasil penelitian ini menyimpulkan bahwa untuk memperbanyak item soal dapat menggunakan teknik paraphrase terutama bagi institusi yang menggunakan system bank soal dalam menghasilkan lebih dari satu set soal.
\end{abstract}

Kata-kata Kunci: Parafrase; butir soal; asesmen; tes berbasis teks 
Jurnal Ilmu Komunikasi UHO : Jurnal Penelitian Kajian Ilmu Komunikasi dan Informasi.

Volume 7, No. 1, Januari 2022, hlm 19-29

\title{
PARAPHRASING TECHNIQUE IN QUANTIFYING TEST ITEM IN COMMUNICATION SCIENCE PROGRAM OF UNIVERSITAS TERBUKA
}

\begin{abstract}
In educational institutions, assessment is an important issue in an effort to measure the success of the student learning process. Examination banks often experience a shortage of question items, especially when new basic material books are published as teaching materials. The required number of items in sets of questions is not met. This will reduce the quality of the assessment itself. The purpose of this study is to provide an alternative question bank in quantifying the item questions using paraphrasing technique. The research stages included creating paraphrasing procedures, trying it out to some test writers, determining paraphrase categories, and deciding which technique is appropriate to a certain test stem or question items. The result of this study conclude that to increase test items, paraphrase techiques can be used, especially for institutions that use a question bank system to produce more than one set of questions.
\end{abstract}

Keywords: Paraphrasing technique; item test; assessment; text-based questions. 
Jurnal Ilmu Komunikasi UHO : Jurnal Penelitian Kajian Ilmu Komunikasi dan Informasi.

Volume 7, No. 1, Januari 2022, hlm 19-29

\section{PENDAHULUAN}

Bentuk baru pendidikan tinggi jarak jauh menggabungkan pembelajaran dan jaringan dengan cara yang inovatif. Ada banyak manfaat menggunakan pendidikan jarak jauh, seperti berbagi sumber daya, menyampaikan pesan dengan cepat, dan mengintegrasikan media pendidikan ke dalam pengalaman pendidikan secara keseluruhan termasuk evaluasi dan penilaian (Tongke, 2013)

Untuk memastikan kualitas pendidikan, evaluasi dan umpan balik sangat penting. Tongke (2013) melanjutkan bahwa pendidikan jarak jauh, di sisi lain, terus mengandalkan penilaian sumatif daripada evaluasi proses. Ini tidak memiliki kerangka teoritis atau kerangka kuantitatif. Guru dan administrator tidak melakukan cukup. Akibatnya, metode evaluasi tradisional tidak lagi berlaku untuk pembelajaran online. Sulit bagi guru untuk melacak siswa mereka dan memberikan umpan balik yang konstruktif di kelas online. Dalam jangka panjang, kurangnya fokus dan motivasi dapat menyebabkan kegagalan. Menurut Koneru (2017) evaluasi adalah siklus kemajuan sebagai bukti peristiwa sosial tentang performa siswa dan menghasilkan masukan yang dapat meningkatkan proses pembelajaran mereka. Dalam pendidikan jarak jauh terbuka, penilaian formatif mendukung siswa untuk menilai sendiri proses belajar mereka dan meningkatkan performa mereka dalam penilaian sumatif.

Oleh karena itu, salah satu aspek pembelajaran yang paling menonjol adalah penilaian. Penilaian, di sisi lain, dapat digunakan untuk berbagai tujuan. Memberikan umpan balik kepada siswa di akhir unit pengajaran adalah salah satu tujuan penilaian. Kebutuhan dan kemampuan siswa juga dapat diidentifikasi dan dipantau melalui penilaian, yang dapat membantu guru lebih memahami kemampuan kognitif siswa yang lebih tinggi. Menilai prestasi, kompetensi, dan kebutuhan belajar siswa dapat membantu siswa meningkatkan keterampilan mereka dengan memanfaatkan informasi yang dapat diberikan oleh penilaian (Isabwe, Reichert, Carlsen, \& Lian, 2014)

Guru atau dosen dan perancang kurikulum dapat menggunakan bank soal untuk meningkatkan evaluasi siswa, keterampilan belajar dan menjawab serta logika bertanya mereka. Bank soal bukanlah alat pembelajaran, melainkan berfungsi sebagai panduan evaluasi diri (Parthasarathy \& Ananthasayanam, 2012).

Di Universitas Terbuka bank soal atau soal berfungsi sebagai sarana penilaian dan evaluasi bagi mahasiswa. Untuk beberapa alasan, bank soal kekurangan jumlah item soal yang memadai, artikel ini mencoba menawarkan solusi dengan menggunakan teknik 
Jurnal Ilmu Komunikasi UHO : Jurnal Penelitian Kajian Ilmu Komunikasi dan Informasi.

Volume 7, No. 1, Januari 2022, hlm 19-29

parafrase. Parafrase dapat menduplikasi butir-butir tes dalam bentuk yang berbeda tetapi tetap memiliki arti yang sama

Prinsip kesetaraan semantik adalah definisi parafrase yang paling banyak diterima. Misalnya, parafrase dapat didefinisikan sebagai bentuk permukaan berbeda yang mengungkapkan makna yang sama dengan aslinya. Ada berbagai tingkat parafrase (Madnani \& Dorr, 2010)Sejauh definisi dan tipologi parafrase yang bersangkutan, Vila, Martí, and Rodríguez (2011) menawarkan kritik yang bijaksana. Tidak ada karakterisasi parafrase yang komprehensif, berbasis linguistik, dan dapat ditelaah secara komputasi. Ketika meninjau tentang definisi dan klasifikasi parafrase, Vila dkk. memberikan kritik yang terinformasi dengan baik. Parafrase tidak memiliki karakterisasi yang dapat diatur secara linguistik atau komputasi

Mengadopsi dari situs web Universitas Simon Fraser memiliki tutorial tentang "Mengutip, Parafrase, dan Meringkas," (https://www.lib.sfu.ca/about/branchesdepts/slc/writing/sources/ quoting-paraphrasing-summarizing), yang menguraikan bahwa parafrase yang memadai yang memiliki beberapa langkah sederhana, yaitu pertama diawali dengan (1) mengidentifikasi bagian pendek (satu sampai empat kalimat) yang mendukung ide di kertas dan memilihnya; (2) untuk mendapatkan hasil maksimal dari proses parafrase, teks perlu dibaca dengan baik. Dengan memahami isi teks yang akan diparafrase akan memudahkan proses parafrase; (3) membuat catatan merupakan cara yang efektif untuk terutama frase-frase yang sering dijumpai dalam suatu tulisan; (4) Agar menghasilkan parafrase yang baik, maka perlu dijaga agar panjang kalimat atau paragraf mendekati bentuk aslinya; yang terakhir (4) memeriksa apakah hasil terlalu mirip denga bentuk aslinya.

Dalam penelitian ini, langkah-langkah tersebut digunakan sebagai panduan atau instrumen pendukung bagi penulis parafrase untuk melakukan pekerjaan parafrase mereka.

Penelitian tentang parafrase telah banyak dilakukan terutama pada bidang ilmu bahasa, ilmu informasi dan komunikasi, dan ilmu komputer. Pada bidang ilmu bahasa, penelitian parafrase kebanyakan pada pendidikan bahasa, ketrampilan menulis (writing) dan penerjemahan, tujuan utama dari parafrse adalah menghindarkan dari plagiarisme yaitu menulis ulang tulisan orang lain seakan-akan menjadi tulisan kita. Seperti yang telah diteliti $\mathrm{Na}$ and Nhat Chi Mai (2017) yang menyatakan bahwa parafrase merupakan keterampilan penting dalam menulis akademik dimana keterampilan kognitif yang membutuhkan pemikiran tingkat tinggi dan kemahiran yang tinggi baik dalam membaca dan menulis. Penelitian ini mengeksplorasi kemampuan parafrase pelajar EFL di perguruan tinggi di 
Jurnal Ilmu Komunikasi UHO : Jurnal Penelitian Kajian Ilmu Komunikasi dan Informasi.

Volume 7, No. 1, Januari 2022, hlm 19-29

Vietnam dan mengkaji tantangan yang mereka hadapi saat parafrase. Temuan mengungkapkan bahwa peserta sering memparafrasekan menggunakan sinonim, tetapi jarang mengubah struktur sintaksis.

Beberapa penelitian memfokuskan paraphrase dalam masalah palgiarisme di sekolah, menurut (Madani \& Ardianti, 2020), parafrase atau parafrasa adalah pengungkapan kembali suatu tuturan bahasa ke dalam bentuk bahasa lain tanpa mengubah pengertian. Pengungkapan kembali tersebut bertujuan untuk menjelaskan makna yang tersembunyi. Ada beberapa hal yang harus dilakukan dalam membuat parafrasa dari sebuah bacaan. Penggunaan teknik parafrase dalam menulis untuk menghindari plagiarisme

Sementara itu Isnawati, Badriyah, and Titin (2021) meneliti mahasiswa yang menyelesaikan proyek penelitiannya di akhir studi yang diwajibkan untuk menulis laporan tugas akhir. Dalam proses pembuatan karya ilmiah tersebut, seharusnya mereka sudah mengetahui dan memahami tentang pentingnya hak cipta dan masalah plagiarisme. Disimpulkan bahwa dengan parfrase mahasiswa mengetahui teknik menulis agar tidak termasuk plagiarisme.

Di samping masalah plagiarisme, penelitian parfrase juga memfokuskan pada bidang pembelajaran mengarang atau menulis di sekolah. Seperti Rosiana and Mulyani (2017) yang menguji keefektifan penggunaan metode parafrase dan metode inkuiri dalam pembelajaran apresiasi puisi berdasarkan minat baca peserta didik SMK. Hasil penelitian ini menunjukkan nilai rata-rata postes dengan menggunakan metode parafrase lebih besar daripada hasil postes dengan menggunakan metode inkuiri.

Sedangkan Salmiati (2015) melakukan penelitian parafrase di Sekolah Dasar yang menyatakan bahwa pembelajaran sering didominasi oleh guru sebagai sumber informasi Berdasarkan pengamatan, ditemukan hasil belajar siswa rendah. Tujuan penelitian ini untuk peningkatan keterampilan menulis parafrase dengan menggunakan metode mind mapping pada siswa.

Sementara itu penelitian Wulandari and Rahmi (2012) menyimpulkan bahwa siswa dalam menulis cerpen mulai antusias dan dapat mengembangkan ide cerita. Teknik parafrase puisi cocok dijadikan teknik untuk menulis cerpen. Usman (2015) melakukan penelitian tindakan kelas. Penelitian ini bertujuan untuk meningkatkan kemampuan menulis siswa dalam memparafrasekan puisi menjadi prosa dan mendeskripsikan bagaimana metode parafrase meningkatkan kemampuan menulis siswa dalam memparafrasekan puisi menjadi prosa. Disimpulkan bahwa metode parafrase dapat meningkatkan kemampuan siswa. 
Jurnal Ilmu Komunikasi UHO : Jurnal Penelitian Kajian Ilmu Komunikasi dan Informasi.

Volume 7, No. 1, Januari 2022, hlm 19-29

Dari peneltian terdahulu dapat disimpulkan bahwa umumnya penelitian paraphrase fokusnya pada bidang atau masalah ketrampilan bahasa dalam hal ini mengarang atu menulis cerita. Selain itu juga masalah plagiarisme di mana mahasiswa yang sedang menulis karya ilmiah mereka sebagi tugas akhir perlu mengetahui tentang plagiarisme.

Dalam penelitian ini parafrase tidak dihubungkan dengan plagiarisme maupun pembelajar menulis, tetapi cenderung pada bagaimana parafrase digunkan untuk menggandakan soal tes untuk para mahasiswa Ilmu Komunikasi di Universitas Terbuka. Teknik parafrase yang digunakan menekankan pada kemiripan makna dan bentuk atau struktur bahasa yang berbeda. Dengan teknik ini diharapkan beberapa perangkat soal dapat dihasilkan dengan lebih cepat dan beberapa perangkat soal memiliki derajat kesulitan yang sama.

\section{METODE PENELITIAN}

Instrumen dalam penelitian ini didasarkan pada empat mata kuliah di Program Studi Ilmu Komunikasi pada Fakultas Hukum, Ilmu Sosial dan Ilmu Politik, Universitas Terbuka. Empat mata kuliah tersebut adalah, 1) Inovasi Komunikasi (Nomor Kode SKOM4316); 2) Sosiologi Komunikasi Massa (Nomor Kode SKOM4205), 3) Perencanaan Program Komunikasi (Nomor Kode SKOM4206); dan 4) Komunikasi Antar Budaya (Nomor Kode SKOM4318). Materi kuliah tersebut semuanya dalam Bahasa Indonesia. Setiap materi pelajaran terdiri dari sembilan modul, dan setiap modul terdiri dari dua atau lebih kegiatan pembelajaran. Dalam instrumen ini masing-masing instrumen dipilih secara acak dari item pertanyaan materi kuliah sebanyak 36 item.

Narasumber penelitian ini adalah empat orang dosen Universitas Jenderal Achmad Yani (UNJANI) Bandung, Universitas Sebelas Maret (UNS) Surakarta, dan Universitas Terbuka (UT). Nara sumber yang bekerja pada bidangnya yang sudah terbiasa menulis soal tes, namun dalam penelitian ini, mereka bertugas untuk memparafrase butir-butir tes. Setiap penulis parafrase harus memparafrasekan dua instrumen yang berbeda dari 72 item parafrase.

Hasil dari proses parafrase kemudian dianalisis menggunakan kategori yang diadopsi dari Vila et al. (2011) dan secara praktis harus disesuaikan dengan aturan dan struktur Bahasa Indonesia (lihat Tabel 1) 
Jurnal Ilmu Komunikasi UHO : Jurnal Penelitian Kajian Ilmu Komunikasi dan Informasi.

Volume 7, No. 1, Januari 2022, hlm 19-29

Tabel 1. Pengkategorian Parafrase diadopsi dari Vila et al. (2011)

\begin{tabular}{lll}
\hline Type of Changes & Substitutions & Bahasa Indonesia version \\
\hline Lexicon based changes & Same polarity substitution & Changing words \\
\cline { 2 - 3 } & Opposite polarity substitution & Changing to oppositions \\
\cline { 2 - 3 } & Deletion & Omitting \\
\cline { 2 - 3 } & Synthetic/analytic substitution & Changing styles \\
\hline $\begin{array}{l}\text { Morphology based } \\
\text { changes }\end{array}$ & Inflectional change & $\begin{array}{l}\text { Tense form substitution } \\
\text { (NA) }\end{array}$ \\
\cline { 2 - 3 } & Derivational change & $\begin{array}{l}\text { Part of speech change } \\
\text { (NA) }\end{array}$ \\
\hline Syntax based changes & Diathesis alternation & Word order \\
\hline Semantics based changes & $\begin{array}{l}\text { Change in the lexicalization } \\
\text { pattern }\end{array}$ & Changing phrases \\
\hline Discourse based changes & Change in the discourse structure & $\begin{array}{l}\text { Change special } \\
\text { phrases/styles }\end{array}$ \\
\hline
\end{tabular}

Sumber: Diadopsi dari Vila dkk (2011)

\section{HASIL DAN PEMBAHASAN}

Parafrase total dari empat kursus adalah 288 item. Teks parafrase dianalisis menurut kategori mereka dari Vila et al. (2011). Secara umum, parafrase teks bahasa Indonesia lebih sederhana daripada bahasa Inggris. Beberapa kasus ditemukan bahwa ada kategori yang jarang ada dalam bahasa Inggris seperti menambahkan kata, mengubah menjadi kalimat pasif. Karena merupakan teks khusus untuk soal tes (bukan teks bebas), ditemukan bahwa kategori perubahan ke pertanyaan atau perubahan ke imperatif sering terjadi dalam parafrase. Dalam analisis ditemukan juga bahwa setiap teks yang diparafrasekan memiliki beberapa kategori lagi.

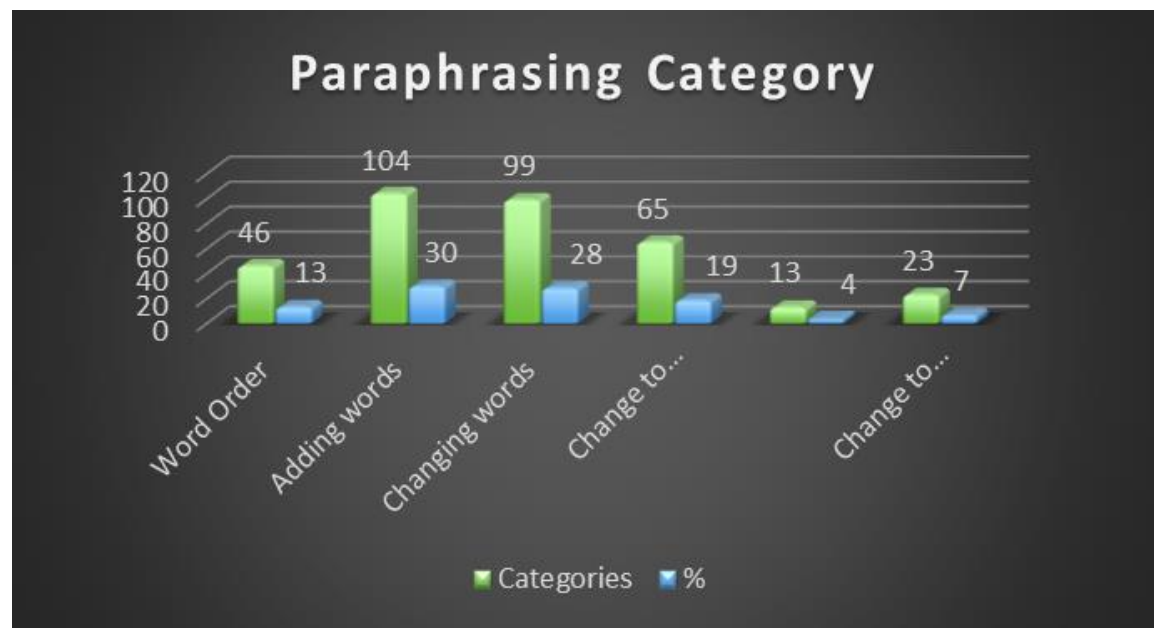

Sumber: Hasil Penelitian (2020)

ISSN: 2527-9173. Website: http://ojs.uho.ac.id/index.php/KOMUNIKASI/index 
Jurnal Ilmu Komunikasi UHO : Jurnal Penelitian Kajian Ilmu Komunikasi dan Informasi.

Volume 7, No. 1, Januari 2022, hlm 19-29

Diagram 1 Hasil Analysis Pengkategorian Parafrase (N=288)

\section{Susunan kata (Word Order)}

Penelitian ini menemukan bahwa kategori urutan kata pada hasil parafrase adalah 13 persen (lihat Diagram 1 di bawah). Dalam menganalisis teks parafrase, ditemukan contoh di bawah ini:

Teks Asli:

Menurut Windahl dan Olson ada beberapa pelaksanaan gatekeeping dalam perencanaan komunikasi ialah...

Teks Parfrase:

Sebutkan beberapa pelaksanaan gatekeeping dalam perencanaan komunikasi menurut Windahl dan Olson!

Frasa di dalam kotak berubah posisi dari depan pindah ke posisi belakang dan maknanya tetap sama dengan teks aslinya. Pada contoh di atas juga terlihat bahwa dalam sebuah teks parafrase memiliki lebih dari satu kategori. Menurut Rijkhoff (2015) bahwa susunan kata dan frasa suatu bahasa selalu signifikan; oleh karena itu, ketika suatu bahasa memungkinkan pola pengurutan alternatif, setiap varian harus dianggap signifikan secara komunikatif. Penelitian lain menemukan bahwa dengan menggunakan sintaks dan urutan kata dari bahasa ibu sebagai panduan, ia dapat memprediksi tidak hanya bagaimana orang mengingat kata-kata, tetapi juga bagaimana mereka merespons rangsangan non-linguistik. (Amici dkk., 2019)

\section{Menambahkan kata (Adding words)}

Kategori menambahkan kata memiliki persentase keseluruhan tertinggi (30\%) dalam analisis parafrase. Contoh di bawah ini menunjukkan hasil parafrase, bahwa tidak hanya menambahkan kata 1 tetapi juga mengubah kata 2 dan berubah menjadi pertanyaan 3 .

Teks Asli:

Setiap alternatif pemecahan masalah akan ${ }^{2}$ suatu program komunikasi dituntut mempunyai syarat berikut:

Teks Parafrase:

Apa ${ }^{3}$ syarat yang harus ada ${ }^{1}$ pada setiap alternatif pemecahan masalah dalam ${ }^{2}$ suatu program komunikasi?? 3

\section{Mengubah kata (Canging Words)}


Jurnal Ilmu Komunikasi UHO : Jurnal Penelitian Kajian Ilmu Komunikasi dan Informasi.

Volume 7, No. 1, Januari 2022, hlm 19-29

Dalam hal parafrase, mengubah kata memiliki persentase keseluruhan tertinggi kedua (28 persen). Pendekatan yang berfokus pada pencocokan kata yang mirip cenderung mengabaikan fakta bahwa makna kata sering kali bergantung pada konteks penggunaannya (Nguyen-Son, Miyao, \& Echizen, 2015). Oleh karena itu, dimungkinkan untuk memperbaiki teks parafrase dengan menambahkan kata atau frasa serupa.

Contoh di bawah ini menunjukkan hasil parafrase, bahwa tidak hanya tetapi juga mengubah kata 1 dan menambahkan kata 2 berubah menjadi imperatif3:

Teks Alsi:

Beberapa kelebihan dari media koran ${ }^{1} \operatorname{diantaranya~adalah}^{2} .$.

Teks Parafrase:

Sebutkan $^{3}$ beberapa kelebihan dari media surat kabar $^{1}$ !

Tabel 2. Contoh Matriks of Teks Asli dan Hasil Pengkategorian Parafrase

\begin{tabular}{|c|c|c|c|c|c|c|c|}
\hline Teks Asli & Teks Parafrase & $\begin{array}{l}\dot{\bar{\theta}} \\
\overline{0} \\
0 \\
0 \\
\overline{0} \\
3\end{array}$ & 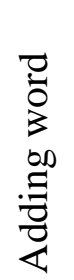 & 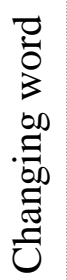 & 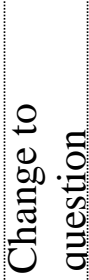 & 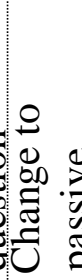 & 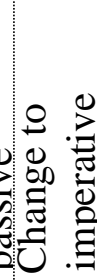 \\
\hline $\begin{array}{l}\text { Menurut Windahl dan } \\
\text { Olson ada beberapa } \\
\text { pelaksanaan gatekeeping } \\
\text { dalam perencanaan } \\
\text { komunikasi ialah... }\end{array}$ & $\begin{array}{l}\text { Sebutkan beberapa } \\
\text { pelaksanaan gatekeeping } \\
\text { dalam perencanaan } \\
\text { komunikasi menurut } \\
\text { Windahl dan Olson! }\end{array}$ & $\sqrt{ }$ & $\sqrt{ }$ & $\sqrt{ }$ & & & $\sqrt{ }$ \\
\hline $\begin{array}{l}\text { Setiap alternatif } \\
\text { pemecahan masalah akan } \\
\text { suatu program } \\
\text { komunikasi dituntut } \\
\text { mempunyai syarat berikut }\end{array}$ & $\begin{array}{l}\text { Apa syarat yang harus } \\
\text { ada pada setiap alternatif } \\
\text { pemecahan masalah } \\
\text { dalam program } \\
\text { komunikasi? }\end{array}$ & & $\sqrt{ }$ & & $\sqrt{ }$ & & \\
\hline $\begin{array}{l}\text { Berdasarkan asal pesan } \\
\text { individu-individu yang } \\
\text { mendefinisikan dirinya } \\
\text { sebagai khalayak ini } \\
\text { memiliki sifat khas yaitu }\end{array}$ & $\begin{array}{l}\text { Apa sifat khas yang } \\
\text { mendefinisikan individu } \\
\text { sebagai khalayak } \\
\text { berdasarkan asal pesan } \\
\text { tersebut? }\end{array}$ & $\sqrt{ }$ & & & $\sqrt{ }$ & & \\
\hline $\begin{array}{l}\text { Menurut Ruben dan } \\
\text { Stewart, dalam menerima } \\
\text { pesan, khalayak } \\
\text { dipengaruhi oleh } \\
\text { sejumlah faktor di } \\
\text { antaranya... }\end{array}$ & $\begin{array}{l}\text { Sebutkan sejumlah faktor } \\
\text { yang memengaruhi } \\
\text { khalayak dalam } \\
\text { menerima pesan menurut } \\
\text { Ruben dan Stewart! }\end{array}$ & $\sqrt{ }$ & & $\sqrt{ }$ & & & $\sqrt{ }$ \\
\hline
\end{tabular}


Jurnal Ilmu Komunikasi UHO : Jurnal Penelitian Kajian Ilmu Komunikasi dan Informasi.

Volume 7, No. 1, Januari 2022, hlm 19-29

\begin{tabular}{|c|c|c|c|}
\hline $\begin{array}{l}\text { Beberapa kelebihan dari } \\
\text { media koran diantaranya } \\
\text { adalah.... }\end{array}$ & $\begin{array}{l}\text { Sebutkan beberapa } \\
\text { kelebihan dari media } \\
\text { surat kabar! }\end{array}$ & $\sqrt{ }$ & $\sqrt{ }$ \\
\hline $\begin{array}{l}\text { Ada beberapa dimensi } \\
\text { dalam segmentasi } \\
\text { khalayak dari suatu } \\
\text { program komunikasi, di } \\
\text { antaranya berdasarkan } \\
\text { karakteristik demografi } \\
\text { yang meliputi hal-hal } \\
\text { berikut .... }\end{array}$ & $\begin{array}{l}\text { Sebutkan beberapa } \\
\text { dimensi segmentasi } \\
\text { khalayak dari suatu } \\
\text { program komunikasi } \\
\text { berdasarkan karakteristik } \\
\text { demografi! }\end{array}$ & $\sqrt{ }$ & $\sqrt{ }$ \\
\hline
\end{tabular}

\section{Sumber: Hasil Penelitian (2020)}

\section{Mengubah Struktur (Changing structures)}

Mengubah ke kalimat tanya, imperatif dan pasif termasuk ke dalam kasus-kasus struktur. memiliki persentase keseluruhan tertinggi kedua (19 persen) dalam analisis parafrase. Contoh di bawah ini menunjukkan hasil parafrase, berubah menjadi pertanyaan. Dalam perubahan struktur, selalu dengan kategori perubahan lainnya

Teks Asli:

Berdasarkan asal pesan individu-individu yang mendefinisikan dirinya sebagai khalayak ini memiliki sifat khas yaitu..

Teks Parafrase:

Apa ${ }^{1}$ sifat khas yang mendefinisikan individu sebagai khalayak berdasarkan asal pesan tersebut ? ${ }^{1}$

\section{SIMPULAN}

Parafrase pertanyaan induk mengubah struktur kalimat, atau mengubah jenis kalimat, atau mengganti kata-kata serupa dari sebuah teks, sehingga diperoleh teks yang berbeda dari teks aslinya. Dengan parafrase, tujuan utama telah tercapai dari teks asli 144 item dan hasil parafrase 288 item mendapatkan total 432 item.

Hasil tes menulis parafrase menunjukkan bahwa kategori parafrase yang paling banyak digunakan adalah Penambahan Kata, Penggantian Kata, Perubahan struktur kalimat yaitu, perubahan dari dan ke bentuk pertanyaan, perubahan dari dan ke bentuk perintah, perubahan dari dan ke bentuk kalimat pasif aktif. Hasil evaluasi penulisan menggunakan teknik parafrase menunjukkan bahwa parafrase memiliki bentuk yang cukup beragam tetapi maknanya tetap sama. 
Jurnal Ilmu Komunikasi UHO : Jurnal Penelitian Kajian Ilmu Komunikasi dan Informasi.

Volume 7, No. 1, Januari 2022, hlm 19-29

\section{DAFTAR PUSTAKA}

Isnawati, U. M., Badriyah, N., \& Titin. (2021). Pelatihan Parafrase Pada Mahasiswa: Upaya Menghindari Plagiarisme Pada Penulisan Karya Ilmiah. Batara Wisnu Journal : Indonesian Journal of Community Services, 1(3). doi:10.53363/bw.v1i3.46

Madani, M. U., \& Ardianti, R. (2020). Teknik Parafrase dalam ketrampilan Menulis untuk Menghindari Plagiarisme. Paper presented at the Prosiding Seminar Nasional PBSIIII Tahun 2020.

Madnani, N., \& Dorr, B. J. (2010). Generating Phrasal and Sentential Paraphrases: A Survey of Data-Driven Methods. Computational Linguistics, 36(3).

Na, C. D., \& Nhat Chi Mai, N. X. (2017). Paraphrasing in Academic Writing: a Case Study of Vietnamese Learners of English. Language Education in Asia, 8(1), 9-24. doi:10.5746/LEiA/17/V8/I1/A02/Na_Mai

Rosiana, S., \& Mulyani, M. (2017). Keefektifan Penggunaan Metode Parafrase dan Metode Inkuiri dalam Pembelajaran Apresiasi Puisi Berdasarkan Minat Baca pada Peserta Didik SMK Negeri 1 Manonjaya dan SMK Nurul Wafa Tasikmalaya. SELOKA, 6(1), 6.

Salmiati, S. (2015). Peningkatan Keterampilan Menulis Parafrase Menggunakan Metode Mind Mapping. Jurnal Pelangi, 8(1), 16. doi:10.22202/jp.2015.v8i1.375

Tongke, F. (2013). Learning Evaluation of Distance Education Based on AHP and Fuzzy Theory. Research Journal of Applied Sciences, Engineering and Technology, 6(9), 1620-1625. doi:10.19026/rjaset.6.3879

Usman, R. (2015). Penggunaan Metode Parafrase untuk Meningkatkan Kemampuan Menulis Parafrase Puisi ke Prosa terhadap Hasil Belajar Siswa Kelas II SMP Al-Ittihat Pekanbaru. Jurnal SOROT, 10(2), 10.

Vila, M., Martí, M. A., \& Rodríguez, H. (2011). Paraphrase Concept and Typology: A Linguistically Based and Computationally Oriented Approach*. Procesamiento del Lenguaje Natural, (46), 8.

Wulandari, Y., \& Rahmi, E. A. (2012). Peningkatan Kemampuan Menulis Cerpen dengan Menggunakan Teknik Parafrase Puisi Siswa Kelas X1 Sma Pertiwi 1 Padang. Varia Pendidikan, 24(2), 26. 